\title{
23. GEOPHYSICAL SURVEYS ON THE ICELAND-FAEROE RIDGE FOR SELECTION OF SITES 336 AND 352
}

\author{
M. Talwani, Lamont-Doherty Geological Observatory of Columbia University, Palisades, New York
}

Although no site surveys were undertaken
specifically for the purpose of selecting sites for drilling
on the Iceland-Faeroe Ridge (Figure 1) during Leg 38,
a number of institutions had earlier conducted geo-
physical surveys on the Iceland-Faeroe Ridge. These
include the German Hydrographic Office (Fleischer et
al., 1974); Durham University: Institute of Oceanology,
Moscow; and Lamont-Doherty Geological
Observatory.
From detailed surveys of bathymetry and magnetics, Fleischer et al. (1974) have constructed a topographic map (Figure 2) and a total intensity magnetic map (Figure 3). The location of four lines along which seismic reflection data were obtained are shown as dashed lines in Figure 1. Lamont-Doherty Geological Observatory collected depth, magnetic, gravity, and seismic reflection data on the Iceland-Faeroe Ridge during Vema Cruises 23, 27, 28, 29, and 30. A sediment isopach map based on Lamont-Doherty data and the four Fleischer profiles are shown in Figure 4 (Kristoffersen and Talwani, in preparation). The three reflection profiler records whose locations are shown in Figure 1, are depicted in Figure 5.

The bathymetric map shows that the Iceland-Faeroe Ridge is nearly flat with a top of about 400 meters. On the northwest side the depths decrease rapidly to the shelf off Iceland and in the east they again decrease rapidly to the Faeroes. Since the depth to the top of the ridge is less than 500 meters, which is considered minimum for drilling, it was decided to locate the sites on the northeast and the southwest flanks of the Iceland-Faeroe Ridge.

On these flanks the sediment thickness increases from under $0.2 \mathrm{sec}$. (double reflection time) to over I sec. double reflection time. Since our objectives were both basement as well as the sedimentary column, we did not want to drill in an area where the sediment thickness was too small, which might have been caused by hiatuses in the sediment deposition, or with sediment thicknesses too large which might make it difficult to reach basement. Therefore, it was decided to locate sites at roughly $0.5 \mathrm{sec}$. double reflection time which would approximately give a depth to basement of about 500 meters.

Although Johnson and Tanner (1972) have suggested that the lineated magnetic pattern of the Reykjanes basin continues north as the Iceland-Faeroe Ridge, such a pattern is not seen clearly on the magnetic intensity map (Figure 3 ). The magnetic intensity map shows a large number of high intensity magnetic anomalies without a very clear pattern. Therefore the drilling sites could not be located with a particular reference to the magnetic intensity values.

Figure 4 shows that Sites 336 and 352 were located on the sides of sediment-covered valleys. At Site 336, the valley is not expressed in the topography, but at Site 352 it is. What appears to be basement is clearly shown on the reflection records in Figure 5, at a depth of about $0.5 \mathrm{sec}$. below the bottom.

\section{ACKNOWLEDGMENTS}

Support for this work came from Contracts N00014-67-A0108-0004 and N00014-75-C-0210 with the U.S. Office of Naval Research and from Grants GA1434, GP5392, GA17731, GA27281, and DES71-00214-A07 from the National Science Foundation.

\section{REFERENCES}

Fleischer, U., Holzkamm, F., Vollbrecht, K., and Voppel, D., 1974. Die Struktur des Island-Faroer-Ruckens aus geophysikalischen Messungen: Sonderdruck aus der Deutschen Hydrographischen Zeitschrift, Band 27, Heft 3, p. 97-113.

Johnson, G.L. and Tanner, B., 1972. Geophysical observations on the Iceland-Faeroe Ridge: Jokull 21. AR, p. 4552.

Kristoffersen, Y. and Talwani, M., in preparation. Geophysical study of the Iceland-Faeroe Ridge: Geol. Soc. Am. Bull. 


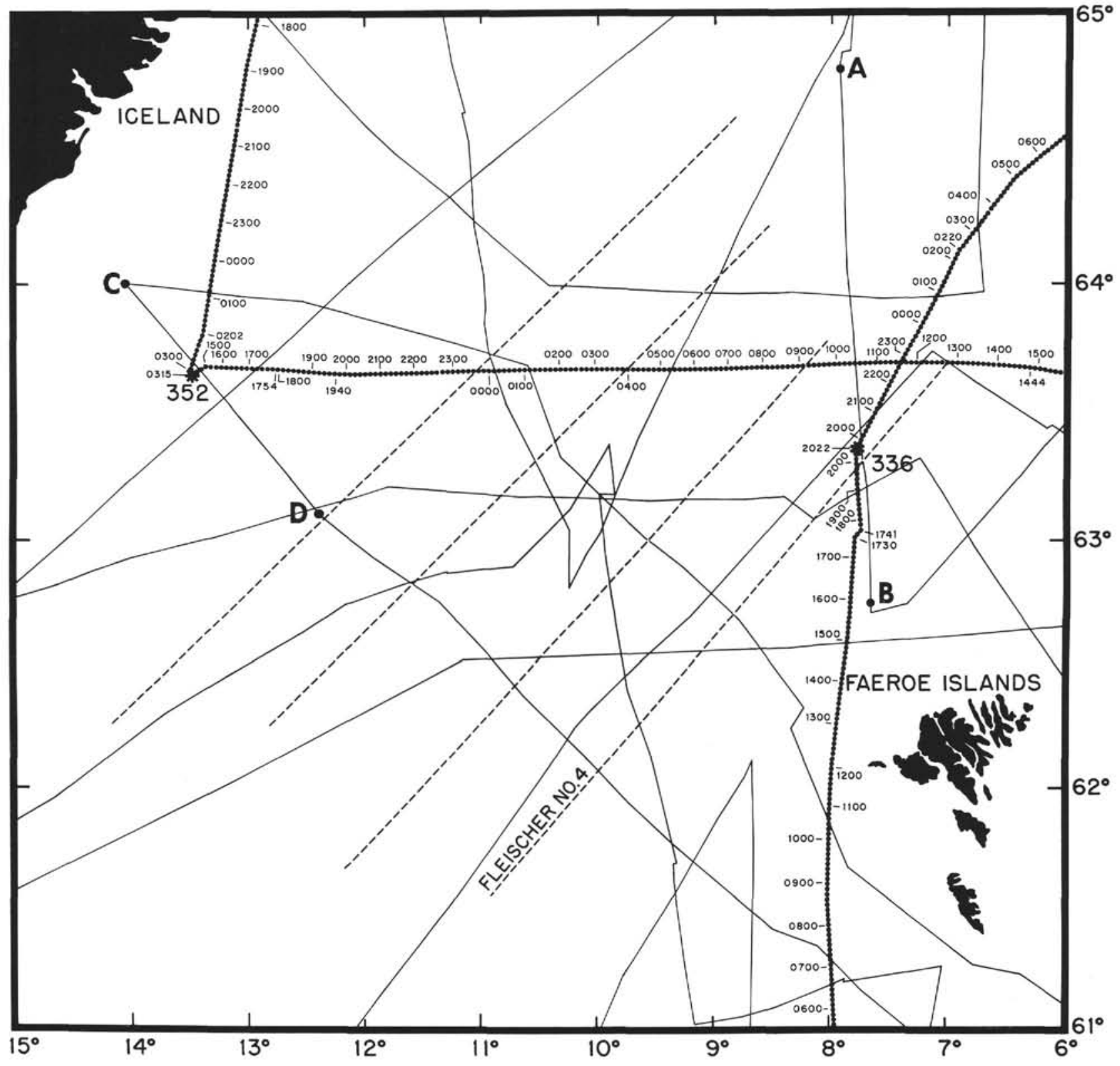

Figure 1. The fine line shows Vema ıracks on Cruises 23, 27, 28, 29, and 30, during which bathymetric, gravity, mag. netic, and seismic reflection data were obtained. The four dashed lines are tracks of Meteor long which seismic reflection were obtained (Fleischer et al., 1974). The thick line gives the track of Glomar Challenger Leg 38. Hour marks are annotated. 


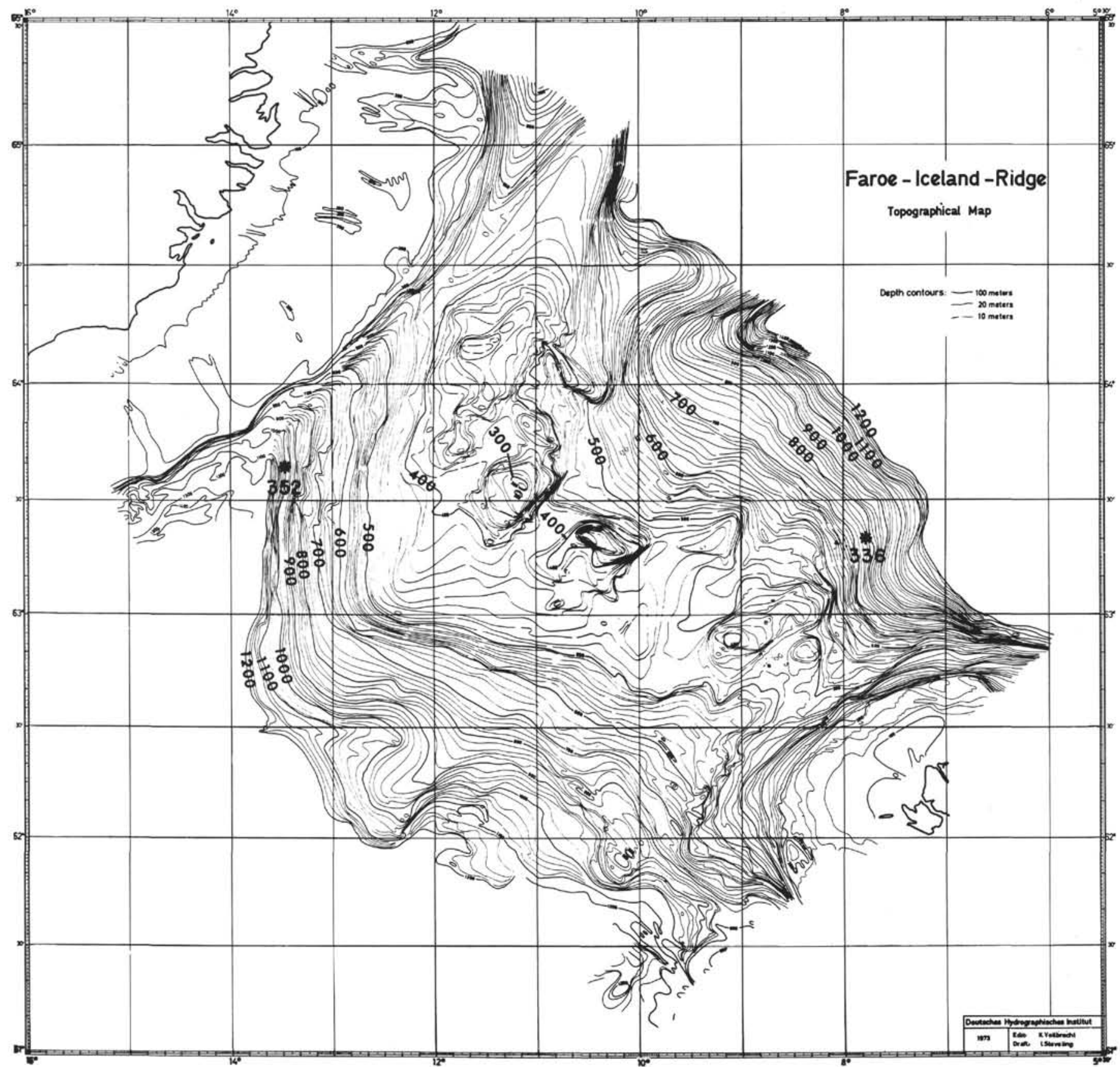

Figure 2. Bathymetric map of Iceland-Faeroe Ridge constructed by Fleischer et al. (1974) reproduced by permission from the Sonderdruck aus der Deutschen Hydrographischen Zeitschrift. 


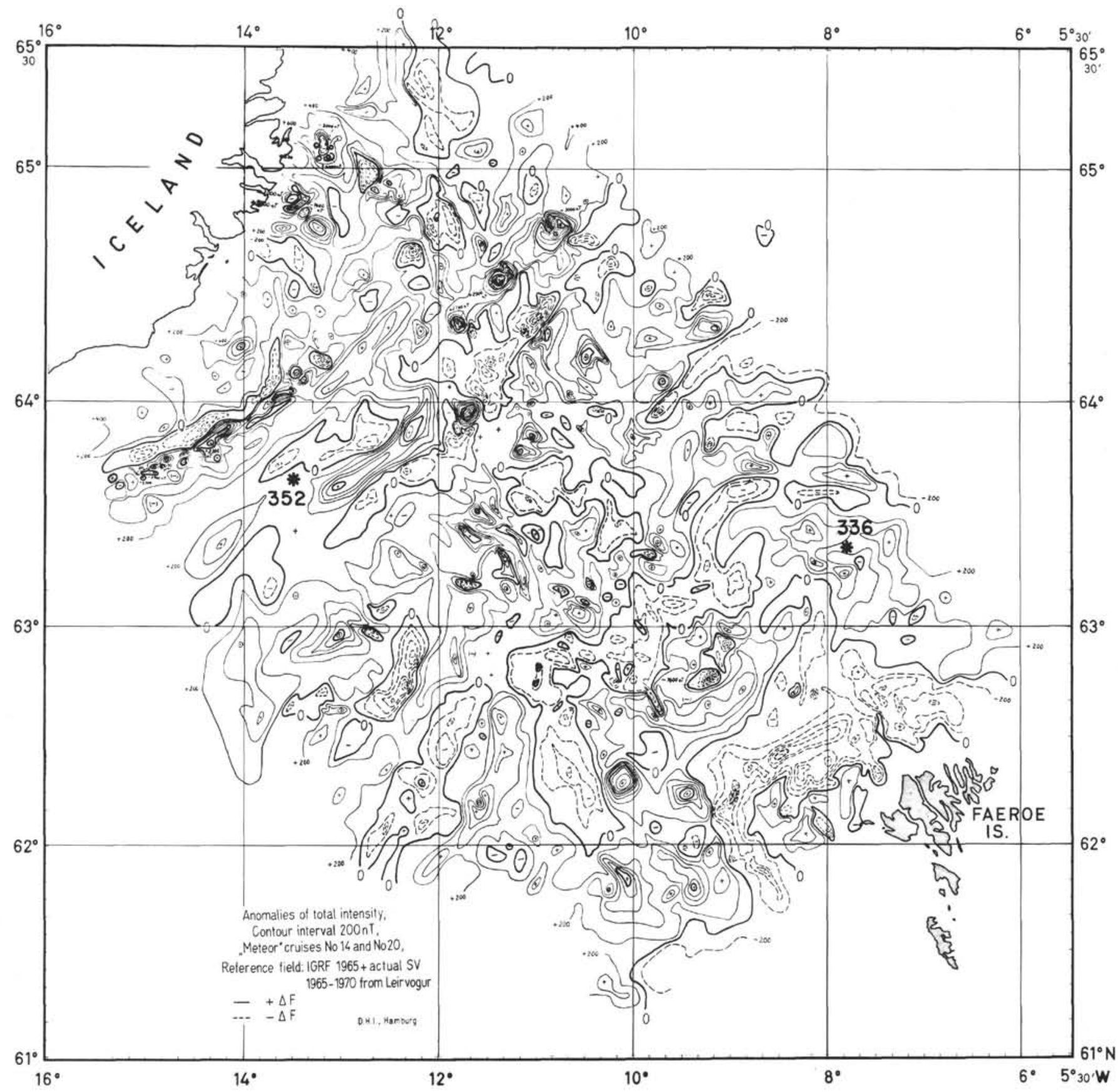

Figure 3. Map is constructed from finely spaced bathymetric lines and is a total intensity magnetic map with reference IGRF removed, also from Fleischer et al. (1974). Reproduced by permission from Sonderdruck aus der Deutschen Hydrographischen Zeitschrift. 


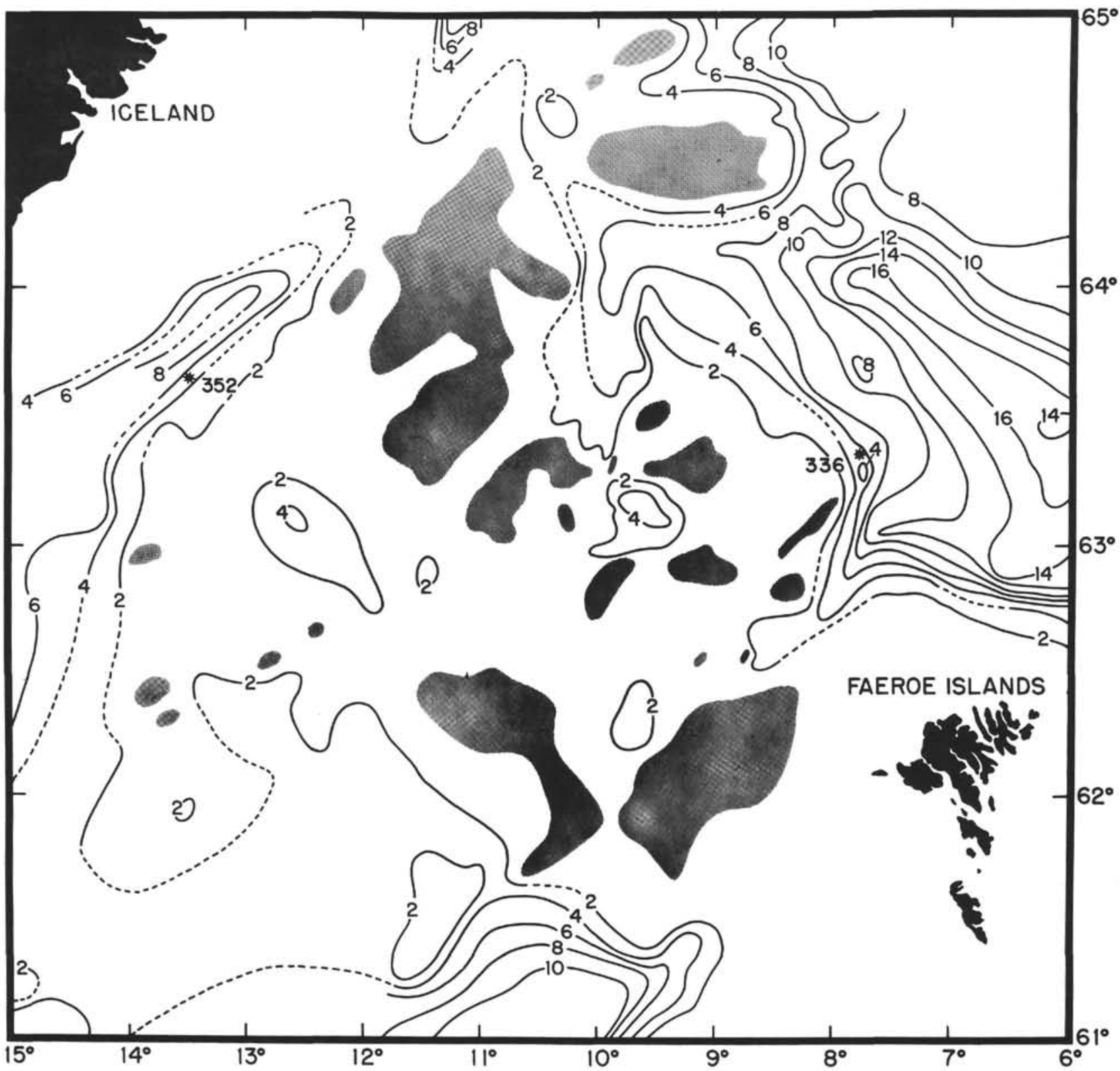

Figure 4. Sediment isopach map of the Iceland-Faeroe Ridge (Kristoffersen and Talwani, in preparation). The contour annotations are two way reflection times in tenths of seconds. The shaded area represents areas where the basement rock apparently outcrops. 

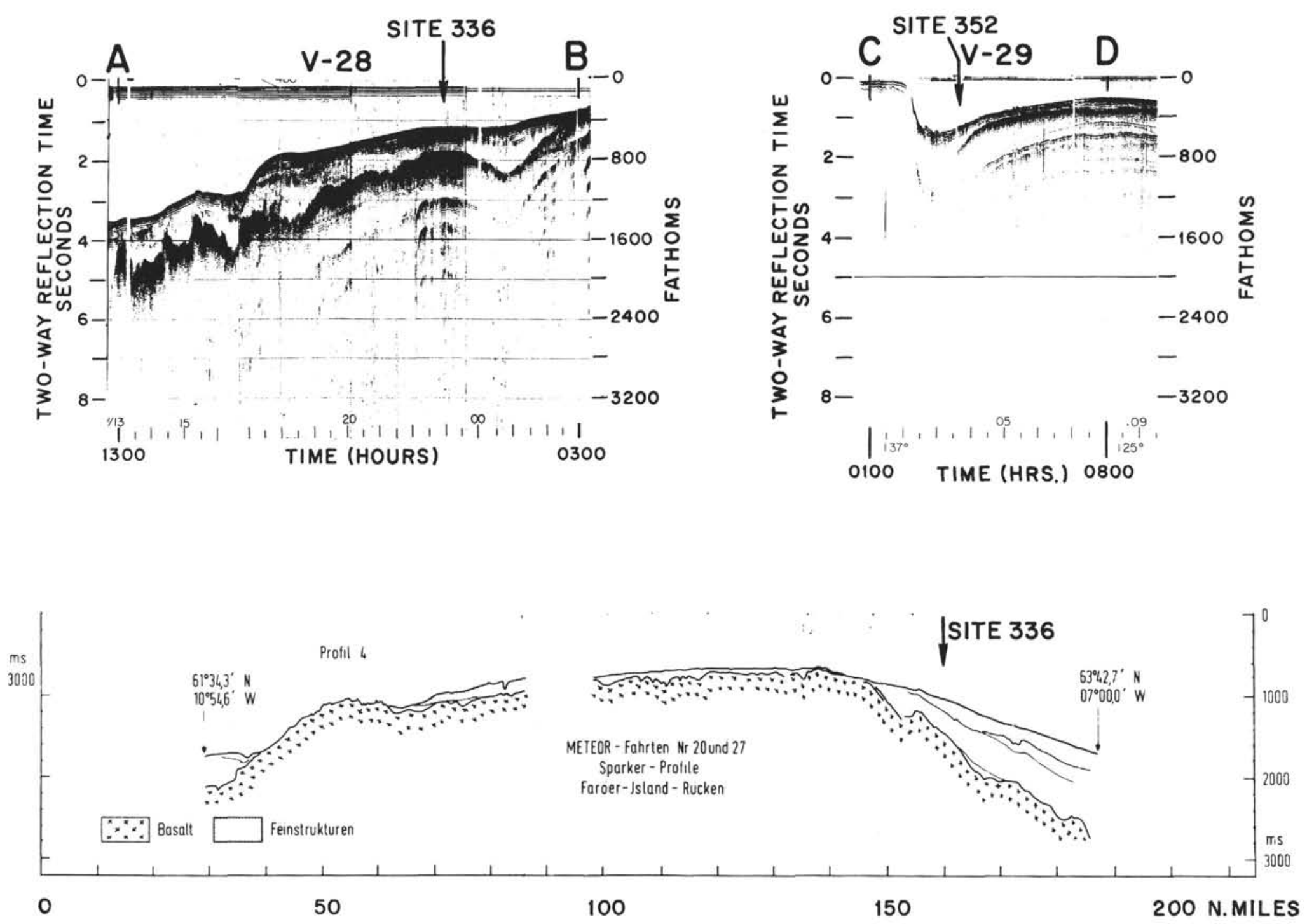

Figure 5. Reflection profiler records on the Iceland-Faeroe Ridge. $A B$ and $C D$ are Vema profiles. Positions are located in Figure 1. The lower profile is from Fleischer et al., 1974. This is Fleischer profile 4, also located in Figure 1. 